\title{
APPLICATION OF MCDA IN THE DETERMINATION OF OPTIMAL BLOCK SIZE FOR OPEN-PIT MODELLING AND MINE PLANNING
}

\author{
Petar Marković $^{1}$, Dejan Stevanović ${ }^{1}$, Milica Pešić Georgiadis ${ }^{1}$, Mirjana Banković ${ }^{1}$
}

Received: April 25, 2021

Accepted: June 09, 2021

\begin{abstract}
The process of creating a geological block model as the basis for a further detailed design and planning of mining operations is a very responsible task. Errors made during this initial process are transferred to all other phases of the mining project. Certainly, one of the most important decisions for the modelling process is the choice of the appropriate size of the blocks that form the model itself. The determination of the optimal block size is not a simple process, because it depends on a large number of affecting factors and criteria. This process can be significantly facilitated by the application of multi-criteria analysis methods, which enable establishment of interdependence between the criteria in order to select the optimal solution. This paper presents the possibilities of applying the Analytical Hierarchical Process (AHP) method for selecting the optimal block size for the needs of the coal deposit modelling process and mine planning, as well as the way in which this method can significantly facilitate problem solving, by looking at it from several aspects. The analysis included six criteria and four potential solutions, and the results themselves indicated the advantages and disadvantages of the applied method.
\end{abstract}

Keywords: block size, multi-criteria analysis, AHP, deposit modelling, mine planning

\section{INTRODUCTION}

In mining projects, the assessment of production profitability, project solutions and production development plans greatly depend on the amount of the estimated resources/reserves, so their correct assessment is crucial for the development of mining projects. Therefore, the block model should be created so that it represents the grades and quantities which can really be obtained from the deposit in the process of excavation by the planned method. Geological block models are numerical 3D networks of small blocks (mini-blocks), arranged in columns, rows and levels, which capture the correct $3 \mathrm{D}$ geometric space in which the deposit is and the required space around the deposit (model space) with different possibilities of their visual display. That means that each block has its own location, size and qualitative characteristics (attributes) in 3D space, as shown in Figure 1. The estimation of resources is based on the block model and the

\footnotetext{
${ }^{1}$ University of Belgrade - Faculty of Mining and Geology, Djusina 7, Belgrade, Republic of Serbia E-mails: markovic.petar910@gmail.com, dejan.stevanovic@ rgf.bg.ac.rs, milica.pesic@ @rgf.bg.ac.rs, mirjana.bankovic@rgf.bg.ac.rs
} 
corresponding cut-off grade, so that blocks with grade above the cut-off are declared as "possible ore" and blocks with grade below as waste. In such delimitation in the design phase, blocks with their grades are the smallest volume units, based on which the delimitation of ore and waste is performed (Sinclair et al., 2002). It follows that, after geological interpretation and geostatistical analysis, the assessment of resources is influenced by two parameters: the block size and cut-off grade.

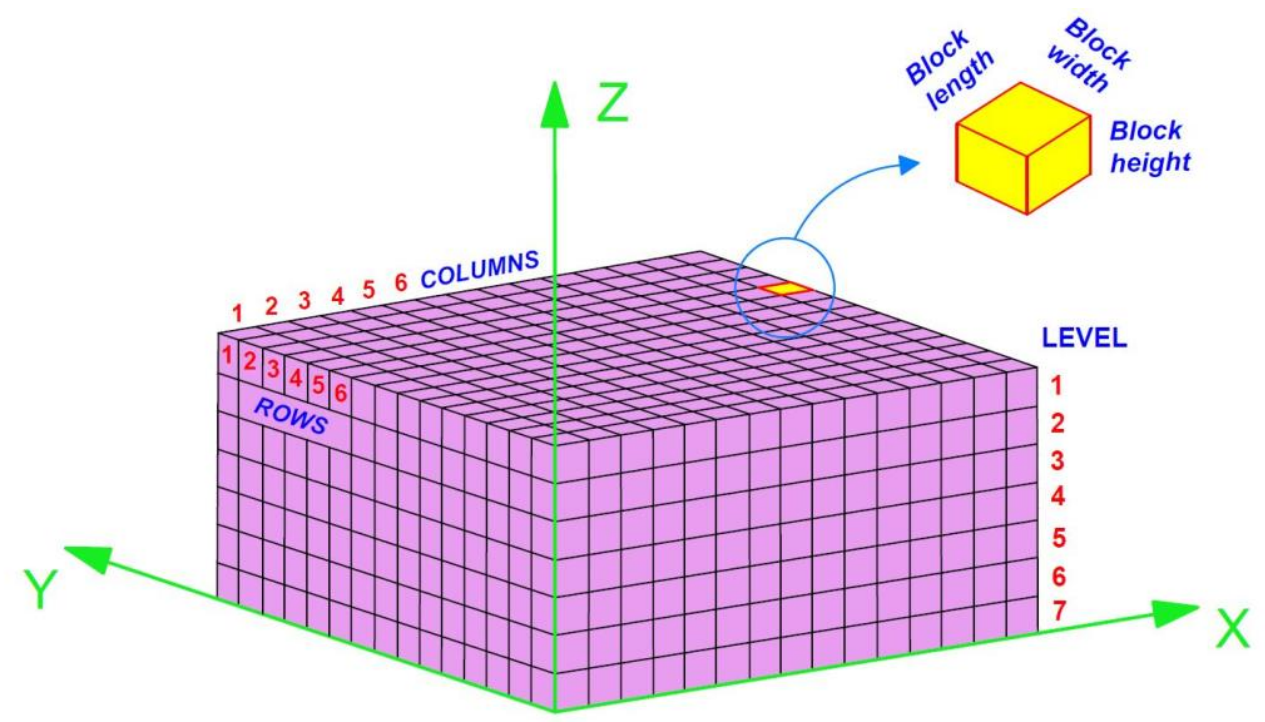

Figure 1 Block model's geometry

The measure of discretization of the model is a problem that generates great controversy in the professional and scientific public. The problem cannot be avoided, and with the definition of the location and dimensions of the modeled space, it occurs at the very beginning of the model creation process (Stevanović, 2015).

The most common mistake made when determining the size of a block is excessive discretization (David, 1971; 1977). This error is inspired by the user desire to present the geological characteristics of the deposit as accurately as possible, which is why they unnecessarily reduce the size of the blocks. By reducing the size of the blocks, the number of blocks in the model is drastically increased, and the time of each operation with the model is further drastically increased (Stevanović, 2015; Stevanović et al., 2020). Also, the distribution of qualitative characteristics in the model may be less accurate if the block size is significantly reduced (Stevanović, 2015).

The selection of the optimal block size is crucial both for the quality assessment of resources and for the process of pit optimization and mine planning, which directly effects on the economy of mining project. A large number of geological, geostatistical, technological and economic parameters have an impact on the choice of the optimal block size, but the two most influential factors are: the distance between exploration 
boreholes and Selective Mining Unit - SMU (Abdollahi et al., 2020). The Selective Mining Unit (SMU) size depends on several different factors, including the mining equipment size, the mining method to be used, the direction of mining and the depositional environment of the orebody (Leuangthong et al., 2003).

Given the large number of factors influencing the block size, as well as the influence of the block size on: geological modelling, pit optimization, mine planning, and the overall project's economy, it can be concluded that choosing the optimal block size is not a simple, straightforward process, and it needs to be solved by considering a large number of interdependent factors. In such cases, the application of multi-criteria decision-making methods is of great importance, since they enable the reduction of values that are difficult to measure and compare with each other, to common factors. These methods have found great application for making appropriate decisions in the field of mining engineering (Abdollahi et al., 2020; Rahimdel et al., 2018; Sitorus et al., 2019; Hayati et al., 2015; Janković et al., 2019; Stevanović et al., 2018; Djenadić et al., 2019). Taking into account the analysis of a set of parameters as well as their individual analysis, the AHP method was recognized as the most favorable in this case, and the results and possibilities of applying this method in determining the optimal block size are presented in this paper.

\section{CASE STUDY: OPEN PIT COAL MINE „UGLJEVIK EAST 1” (UGLJEVIK ISTOK 1)}

Coal mine „Ugljevik East 1" will serve as a replacement for the surface mine „Bogutovo Selo" and continuous supply of Thermal Power Plant Ugljevik for the planned life. The deposit itself consists of three coal seams, i.e. the main coal seam and two roof coal seams. The main coal seam is a very tectonic complex and it is intersected by a large number of mechanical discontinuities, with a broken contour which is the product of complex rupture deformations.

The assessment of the resources of the „Ugljevik East 1" deposit was made on the basis of the method of polygons and profiles which are the basis for creating solids. The solids are then discretized with 3D blocks in order to obtain a 3D block model of the deposit. A solid representation of all three coal seams is given in Figure 2. 


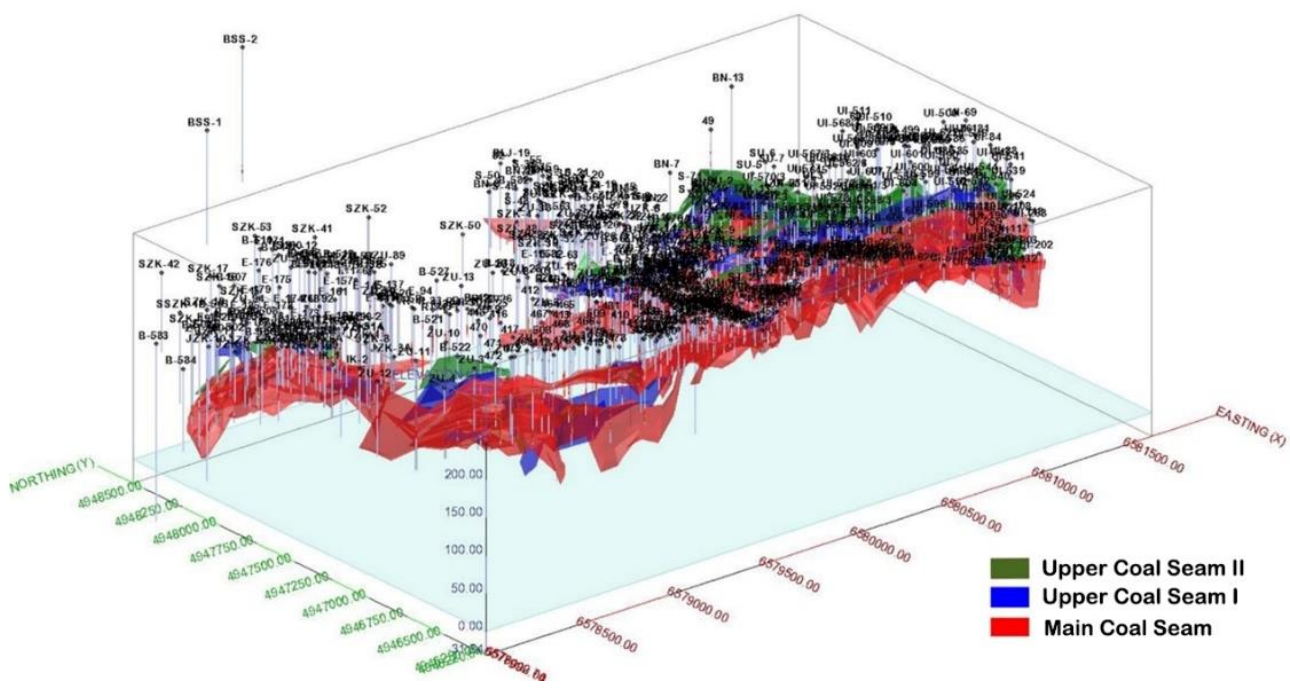

Figure 2 View of the solids of the main, first and second roof coal seams

\section{MULTI CRITERIA DECISION MAKING METHOD - AHP METHOD}

The Analytical Hierarchical Process (AHP) developed by Thomas Saaty (Saaty, 1980), is a decision-making analysis tool, designed to help decision-makers solve complex decision-making problems, by involving multiple criteria over multiple time periods (Cupić at al., 2001). This method is one of the best known and most applied in the analysis of existing data.

AHP is an intuitive method for formulating and analyzing a decision, which can be successfully used to measure the relative impact of numerous, relevant factors on possible outcomes, as well as to predict, derive a distribution of relative probabilities of outcomes (Saaty, 1987). The analytical hierarchical process belongs to the class of methods for soft optimization. It is basically a specific tool for forming and analyzing decision-making hierarchies. AHP first enables the interactive creation of a hierarchy of problems as a preparation of decision scenarios, and then the evaluation, in pairs of elements, of the hierarchy (goals, criteria and alternatives) from top to bottom (Figure 3 ). In the end, the synthesis of all evaluations is performed and the weight coefficients of all elements of the hierarchy are determined according to a strictly determined mathematical model. The sum of the weight coefficients of the elements at each level of the hierarchy is equal to one, which allows the decision maker to rank all the elements horizontally and vertically (Saaty T. L.; Varga L. G., 2012). 


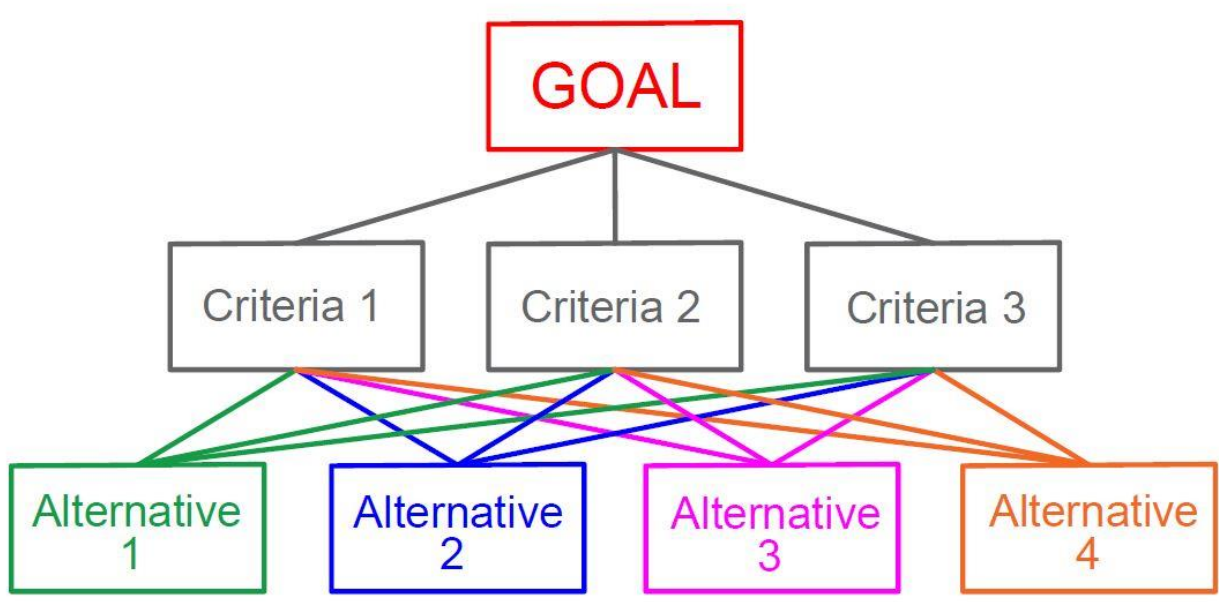

Figure 3 Scheme of hierarchy levels of AHP

During the application of the AHP method in solving the problem of evaluation and ranking of alternatives, there are six basic steps (Lee at al., 2008):

1. Definition of the unstructured problem,

2. Development of the hierarchy of interconnected decision-making elements that describes the problem,

3. Comparison of pairs of decision elements, using the Saaty comparison scale (Figure 4), to obtain input data,

4. Prioritization by calculating the relative weights of decision-making elements, which are afterwards combined into the total priority alternatives,

5. Checking of the consistency of the decision maker,

6. Obtaining of the overall ranking.

The comparison between the two elements of the model hierarchy is performed using the Saaty scale given on Figure 4.

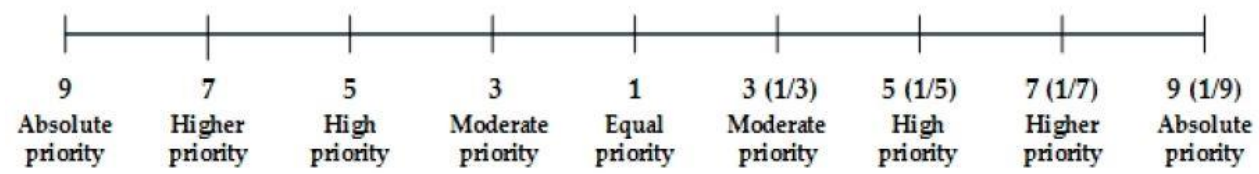

Figure 4 Saaty scale for defining priorities 
The significance, definition and explanation of the scale are shown in Table 1.

Table 1 Significance, definition, and explanation of the Saaty scale

\begin{tabular}{|c|c|c|}
\hline No & Value of the Category & Description \\
\hline 1 & Same value & Two elements are the same \\
\hline 3 & Week dominance & $\begin{array}{l}\text { Experience or judgment are in slight favor of } \\
\text { one }\end{array}$ \\
\hline 5 & Strong dominance & $\begin{array}{l}\text { Experience or judgment are in significant favor } \\
\text { of one element compared to other }\end{array}$ \\
\hline 7 & Demonstrated value & Dominance of one value confirmed in practice \\
\hline 9 & Absolute dominance & Dominance of the highest level \\
\hline $2,4,6,8$ & Inter value & Compromise needed, or further division \\
\hline
\end{tabular}

The mathematical sequence of the calculation of the AHP method begins with a mutual comparison of the two elements, which is done by applying the aforementioned Saaty scale. As a result of comparing element pairs, a numerical value is obtained that represents the weight criterion rate (W). The weight coefficients are calculated for each element at a certain level, by Eq. 1, after which a matrix M is formed (Saaty, 2003), the calculation of which gives the values of preferences (according to the Eq. 2).

$$
\begin{gathered}
W=\sum_{j=1}^{n} \frac{W_{i}}{W_{j}}=w_{i}\left(\sum_{j=1}^{n} \frac{1}{W_{j}}\right) \quad i=1, \ldots, n \\
M=\left[\begin{array}{llll}
\frac{w_{1}}{w_{1}} & \frac{w_{1}}{w_{2}} & \cdots & \frac{w_{1}}{w_{n}} \\
\frac{w_{2}}{w_{1}} & \frac{w_{2}}{w_{2}} & \cdots & \frac{w_{2}}{w_{n}} \\
\frac{w_{n}}{w_{1}} & \frac{w_{n}}{w_{2}} & \cdots & \frac{w_{n}}{w_{n}}
\end{array}\right]=\left[\begin{array}{lll}
a_{11} & a_{12} \cdots & a_{1 n} \\
a_{21} & a_{22} \cdots & a_{2 n} \\
a_{n 1} & a_{n 2} \cdots & a_{n n}
\end{array}\right]
\end{gathered}
$$

The determined vector of weight coefficients is multiplied by the weight coefficient of the higher-level element used as a criterion in the comparison. The procedure is repeated for the lower levels of the hierarchy. Weighting coefficients are calculated for each element at a given level, and they are then used to determine composite relative weighting coefficients of elements at lower levels. Finally, the alternative with the highest composite weighting factor is chosen.

Given that the number of comparisons is often large, the decision maker is rarely consistent with judging and evaluating the value or relationship of qualitative parameters of the problem. Reasoning errors are measured by calculating the Consistency Index (CI) 
for the obtained comparison matrix, and then the Consistency Rate (CR). The consistency index (CI) is calculated according to the Eq.3:

$$
C I=\frac{\lambda_{\max }-n}{n-1}
$$

Where $\lambda_{\max }$ is the maximum eigenvalue of the comparison matrix. The closer $\lambda_{\max }$ is to the number $\mathrm{n}$ (number of analyzed objects), the smaller the inconsistency will be.

The Consistency Ratio (CR) is defined using the following Eq.4:

$$
C R=\frac{C I}{R I}
$$

where RI is the Random Consistency Index, which depends on the number of analyzed objects $\mathrm{n}$, and it is taken from Table 2 (Saaty, 1980).

\begin{tabular}{|c|c|c|c|c|c|c|c|c|c|c|c|c|c|c|c|}
\hline n & 1 & 2 & 3 & 4 & 5 & 6 & 7 & 8 & 9 & 10 & 11 & 12 & 13 & 14 & 15 \\
\hline RI & 0.0 & 0.0 & 0.58 & 0.9 & 1.12 & 1.24 & 1.32 & 1.41 & 1.45 & 1.49 & 1.51 & 1.48 & 1.56 & 1.57 & 1.59 \\
\hline
\end{tabular}

Table 2 The values of the Random Consistency Index (RI) (Saaty, 1980)

If the Consistency Rate (CR) is less than 0.10 , the result is sufficiently accurate and there is no need for corrections in comparisons and repetition of calculations. If the Consistency Rate is greater than 0.10 , the results should be re-analyzed and the reasons for inconsistency established be removed by repeating the comparison of pairs. If repeating the procedure in several steps does not lead to a decrease in the Consistency Rate to a tolerable limit of 0.10 , all results should be discarded and the whole evaluation procedure repeated.

\subsection{Overview of analyzed criteria}

The application of the AHP method implies a multi-criteria analysis, and for the purposes of this paper, the six following criteria are analyzed:

[1] Selective mining unit (SMU),

[2] Geometry of an open pit (bench height),

[3] Distance between investigative works,

[4] Time to generate results,

[5] Interpretation of deposit structure,

[6] Dilution. 
Each criterion is shortly described in the following text.

Selective mining unit (SMU). Selective mining unit (SMU) can be defined as the smallest volume of material on which ore waste classification is determined. This parameter is categorized as one of the most important for choosing the appropriate block dimension in the model. The SMU size depends on a number of different factors, including the mining equipment size, the mining method to be used, the direction of mining, and the depositional environment of the orebody (Leuangthong et al., 2003).

It is important to note that the excavation of coal at the open pit „Ugljevik East 1", implies a methodology of selective excavation, by hydraulic excavators with smaller bucket volumes (due to better selective work). Selective digging of coal, in the excavator block, is done in a certain order of digging from bench top to bottom, as shown in Figure 5. First, coal is excavated in the upper part of the block (bench) until contact with the waste interlayer in the maximum length of the mining block and loaded into the truck, then the waste interlayer is dug and loaded directly into the truck. Finally, coal is excavated in the lower part of the bench. Special care must be taken when applying this method to ensure that there is no possibility of mass sliding in contact with the waste interlayer.

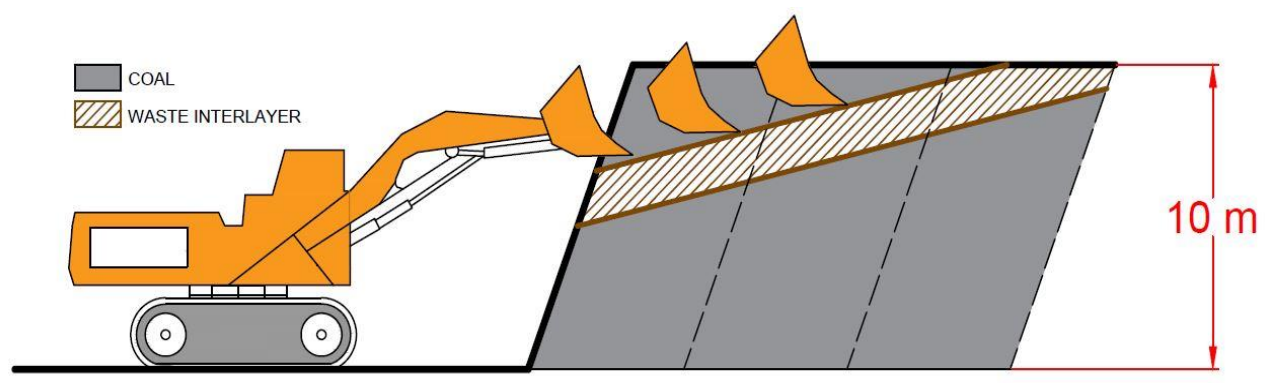

Figure 5 Scheme of excavator operation during excavation of coal and waste interlayers

This way of advancing the excavator block enables the excavation of waste interlayers equals or larger than $0.5 \mathrm{~m}$ of height, with a small impact on losses and dilutions. The height of $0.5 \mathrm{~m}$ represents the lower limit of selectivity (SMU size), which has a significant impact on the dimensions of individual blocks in the model.

Geometry of an open pit (bench height). The boundaries of the surface mine in the west, south and partly in the north are determined by the geology of the deposit (coal thinning, coal seam depth). North-Eastern and eastern boundary of the open pit is not the geological, but the demarcation boundary with the neighboring concessionaire.

The geometric elements of the open pit mine „Ugljevik East 1" are harmonized with the existing practice of mining operations. Based on the geomechanical parameters of the 
working environment, the following angles of the final slopes of the surface mine "Ugljevik East1" were defined:

- The angle of the northern and eastern final slopes of the excavation $26^{\circ}$

- The angle of the southern final slope of the excavation $16^{\circ}$

The open pit "Ugljevik East 1" is divided into the benches of $10 \mathrm{~m}$ height. The optimal bench height was determined based on several influencing factors. The height of the bench is mainly determined based on the requirements of the technological process, losses and dilutions as well as the capacity of the open pit.

Considering that the excavation is performed with benches on which both coal and waste are presented, from the aspect of achieving the required quality (higher selectivity), lower bench heights are preferred. Excavation losses and dilutions are directly proportional to the height of the bench. In Figure 6 the basic geometrical elements of the final slope are shown.

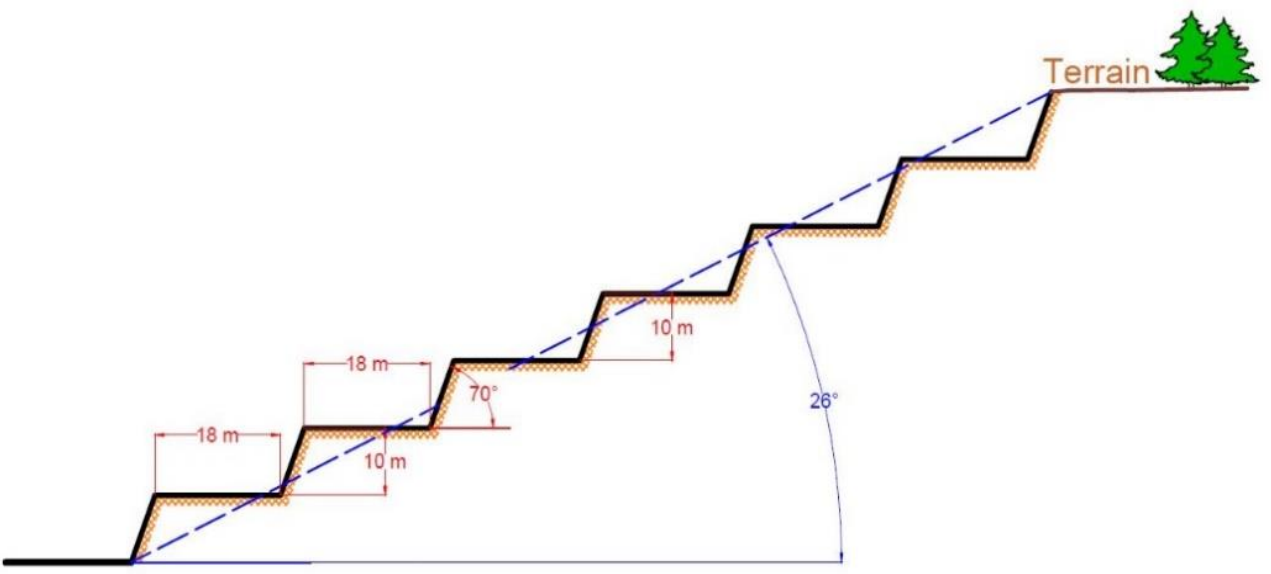

Figure 6 Basic geometric elements of the final slope

Given that the height of the bench is $10 \mathrm{~m}$ for this analysis, the $\mathrm{Z}$ - dimension of individual blocks in the model is limited to the height of $10 \mathrm{~m}$. Adoption of larger block dimensions along the ,Z axis" would not describe the open pit geometry accurately.

Distance between investigative works. For the purpose of creating a geological model of the „Ugljevik East 1" coal deposits, a database was created, containing data for 628 drill holes. The location of all exploration drill holes at the deposit, as well as the boundary of the modelling space, are shown on Figure 7. This disposition of exploration works forms a grid of drill holes measuring $50 \mathrm{~m} \times 50 \mathrm{~m}$. The industry rule and recommendation is that the block size should be in the range from $1 / 3$ to $1 / 2$ of the drill 
hole data spacing (Journel, A. G.; Huijbregts, C. J., 1978). This practically means that the selected block's maximum size along ,X and $\mathrm{Y}$ axis” should be $25 \mathrm{~m}$, in this case.

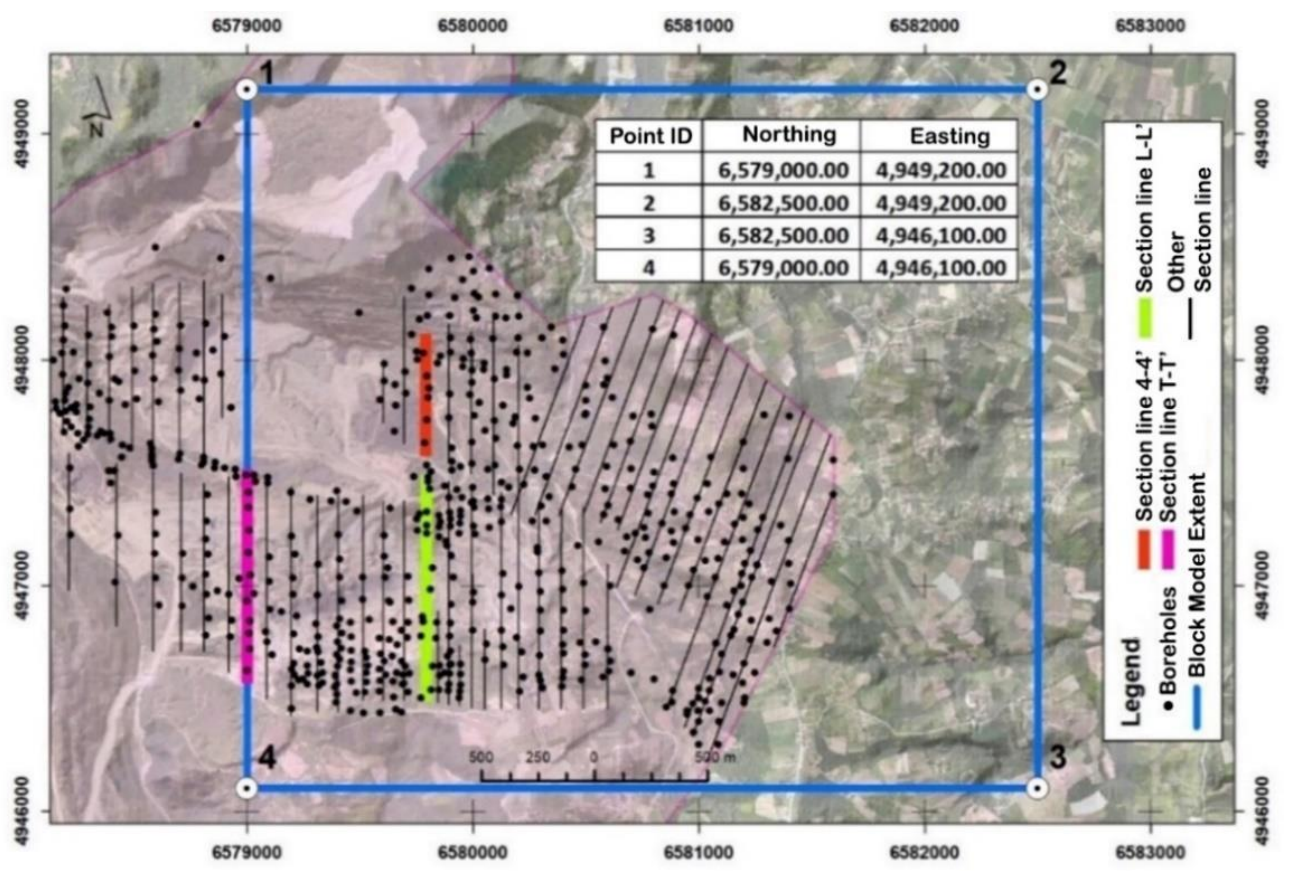

Figure 7 Location of exploration drill holes and modelling space boundary

Time to generate results. Coal deposits usually have complex structures, with a large number of layers and interlayers. In addition to this, open-pit coal mines usually cover a large area and are increasingly of significant depth. Appropriate interpretation of complex coal deposits requires a discretely defined geological model, and in the case of a block model, this implies blocks of small dimensions. All the above, consequently lead to a large number of blocks in the model. In the application of modern methods of pit optimization, the time required for analysis increases disproportionately to the increase in the number of blocks in model. For models with a significant number of blocks, this effect is so pronounced that optimization cannot be carried out within reasonable time frames. The problem has been partially reduced by the development of information support, but it has still not been eliminated (Stevanović et al., 2020).

In order to show the effect of the number of blocks on the duration of optimization process, an analysis of the required optimization time was performed, with a change in the dimension of the blocks along the Z-axis (in the range from $1 \mathrm{~m}$ to $10 \mathrm{~m}$ ). Block length and width remain constant (Stevanović et al., 2020). A diagram with the results of an analysis is shown in Figure 8. 
It should also be noted that, beside pit optimization, in mine planning process there are numerus other operations performed involving block model (scheduling, reserves calculations, cut-off and quality optimization etc.). Even though engineering time (in relation to other project costs) is relatively inexpensive, it still has value. To perform all necessary calculations within the expected time limits, long-lasting block model operations often result in a reduction in the number of the analysis and evaluation of the project's potential scenarios. Consequently, this can greatly undermine the search for project optimal solutions and jeopardize planned business results.

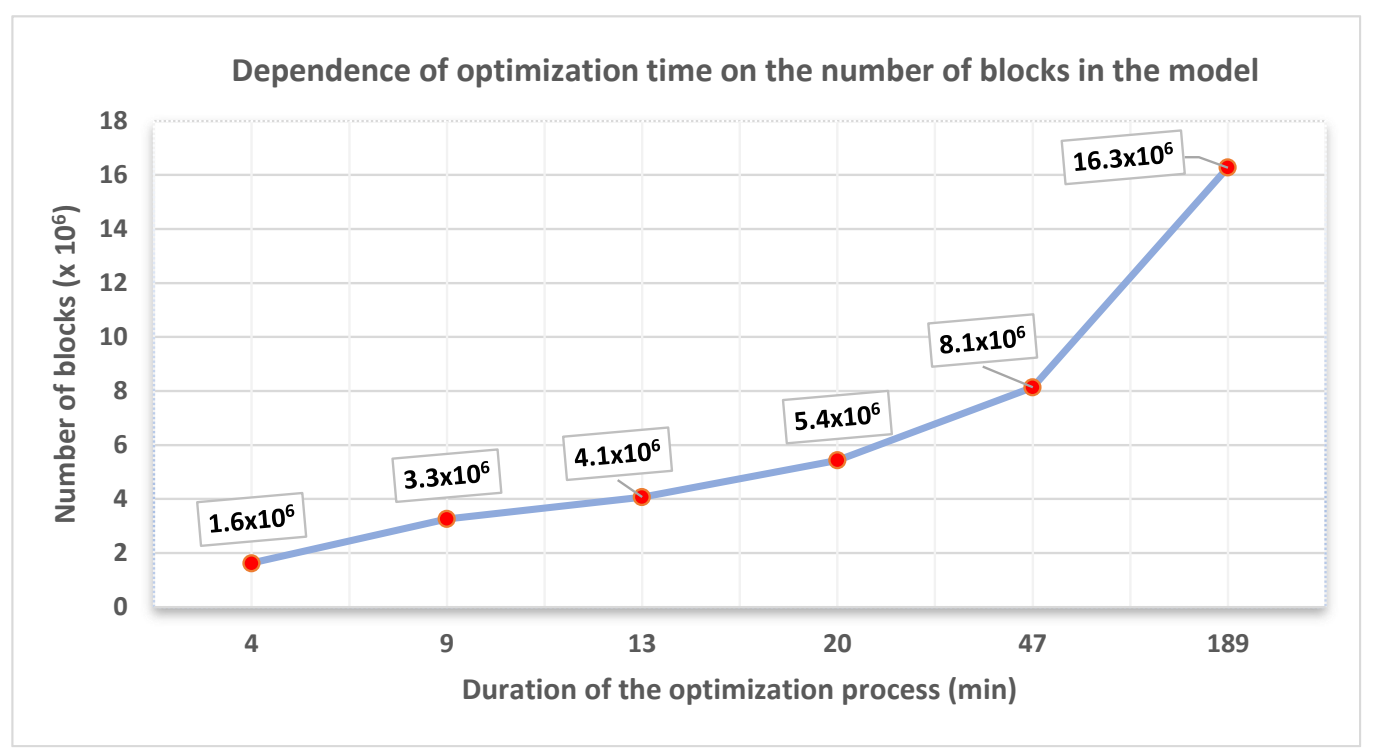

Figure 8 Diagram of the dependence of the optimization time on the number of blocks in the model (Stevanović et al., 2020).

Interpretation of deposit structure. The coal deposit "Ugljevik East 1" consists of three coal seams. The most productive part of the deposit is the main coal seam, the thickness of which is from 20 to 30 meters (with interlayers). The remaining two seams are the first and second roof coal seams with maximum determined thickness of the $5 \mathrm{~m}$. Geologically defined thinnest coal layers (in all three seams) range from 0.1 to $0.3 \mathrm{~m}$.

The interpretation of such complex coal deposits through block models (explicit modelling) has several shortcomings. These shortcomings are related to the very nature of the block model, which makes their elimination impossible. The rigid structure of the block model requires significant discretization (very small blocks) in order to accurately reproduce the complex structure of the coal seams. In Figure 9, a profile is given with the interpretation of the coal seam using a block model. The picture shows the influence of the block size on the adequate interpretation of the coal deposit, as well as the significance that the block size may have on the accuracy, i.e. imprecision of the interpretation (Stevanović et al., 2020). 

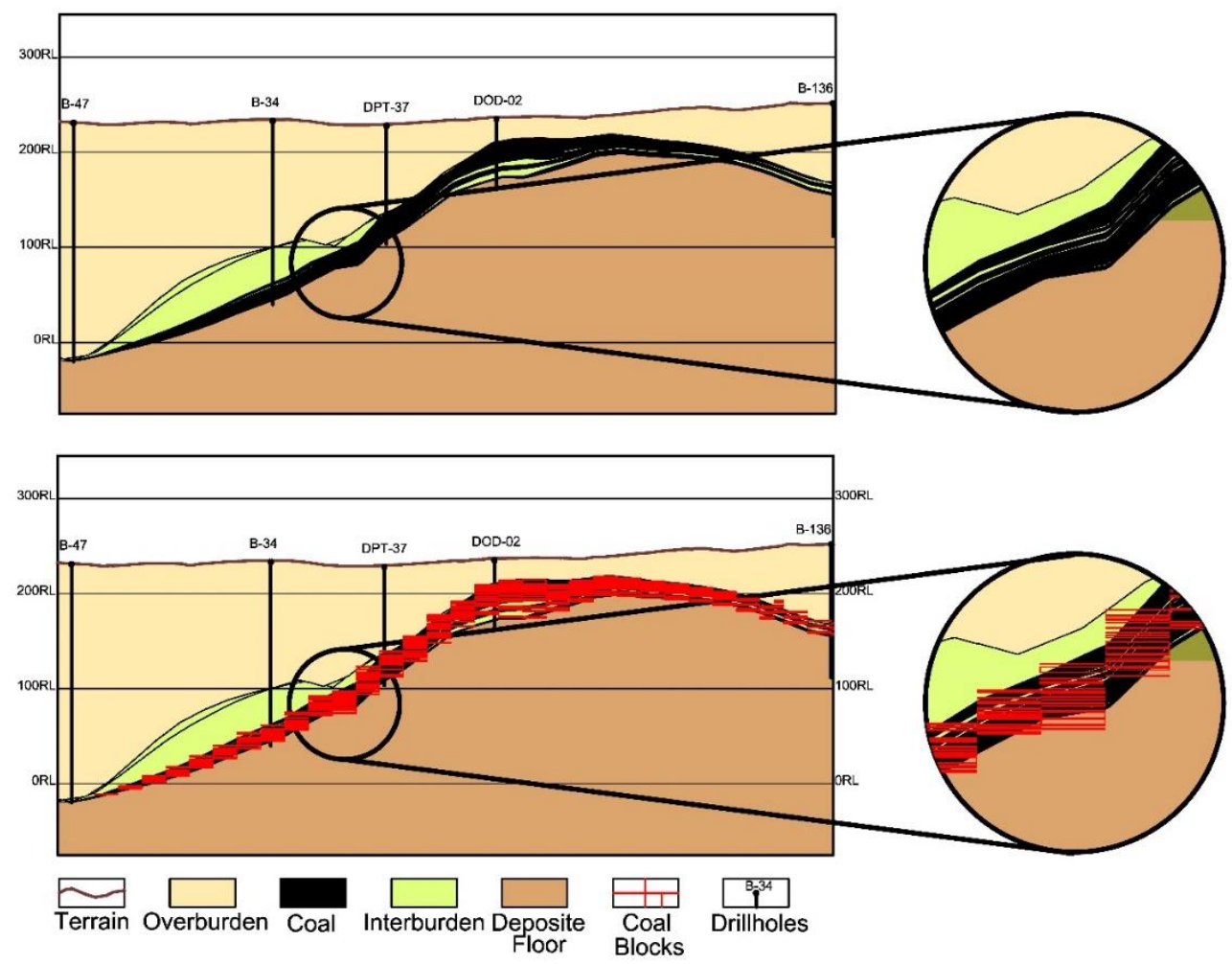

Figure 9 Display of the coal seam interpreted using a block model (Stevanović et al., 2020).

Dilution. The process of the ore excavation from the massif inevitably causes certain differences between the obtained product and the calculated quantities and qualities from the model. These differences are caused by the mixing of the ore and the surrounding material and can be of different intensity depending on several factors.

The amount of surrounding material that is captured along with the excavated ore, which reduces the quality, is called dilution. Since the profitability of mining is sensitive to grade changes, dilution is a critical variable in the evaluation of deposits, and one of the most important factors involved in the mining project economics. This factor is closely related to the recovery rate so that the recovery is decreased with increase in the amount of dilution (Abdollahi, 2020). The impact that block size has on ore quantities and contents is well illustrated by Coombes (2004), (Figure 10). 


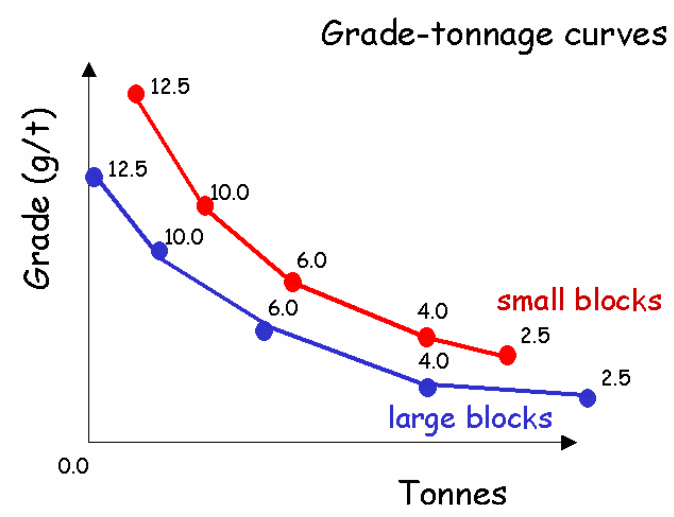

Figure 10 Changes in quantity and grades depending on the different block size (Coombes, 2004)

The graph from Figure 10 shows that smaller blocks give higher grades, but the possibility of their selective excavation is decreased and becomes questionable. Larger blocks, which are more realistic selective units for a particular method of excavation, have a higher dilution and include a larger amount of rock per unit of metal in the resources, and thus affect the assessment of exploitation economy.

\subsection{Solution alternatives}

Taking into account the limitations that the previously described criteria have on the choice of the appropriate block size, it can be concluded that the recommended block size on the $\mathrm{X}$ and $\mathrm{Y}$ axis should range from $12.5 \mathrm{~m}$ to $25 \mathrm{~m}$ (exploration works forms a grid of drill holes measuring $50 \mathrm{~m} \times 50 \mathrm{~m}$ ), while along the $\mathrm{Z}$ axis it should be between a minimum of $0.5 \mathrm{~m}$ (SMU size) and a maximum of $10 \mathrm{~m}$ (bench height). In line with these constraints, four alternatives were chosen for analyses of the appropriate block size:

1. Block size with dimensions $20 \mathrm{~m} \times 20 \mathrm{~m} \times 1.0 \mathrm{~m}$ (Alternative $\mathrm{A}_{1}$ ),

2. Block size with dimensions $20 \mathrm{~m} \times 20 \mathrm{~m} \times 2.5 \mathrm{~m}$ (Alternative $\mathrm{A}_{2}$ ),

3. Block size with dimensions $15 \mathrm{~m} \times 15 \mathrm{~m} \times 5.0 \mathrm{~m}$ (Alternative $\mathrm{A}_{3}$ ),

4. Block size with dimensions $15 \mathrm{~m} \times 15 \mathrm{~m} \times 10 \mathrm{~m}$ (Alternative $\mathrm{A}_{4}$ ).

The final structure of the problem hierarchy is presented in Figure 11. 


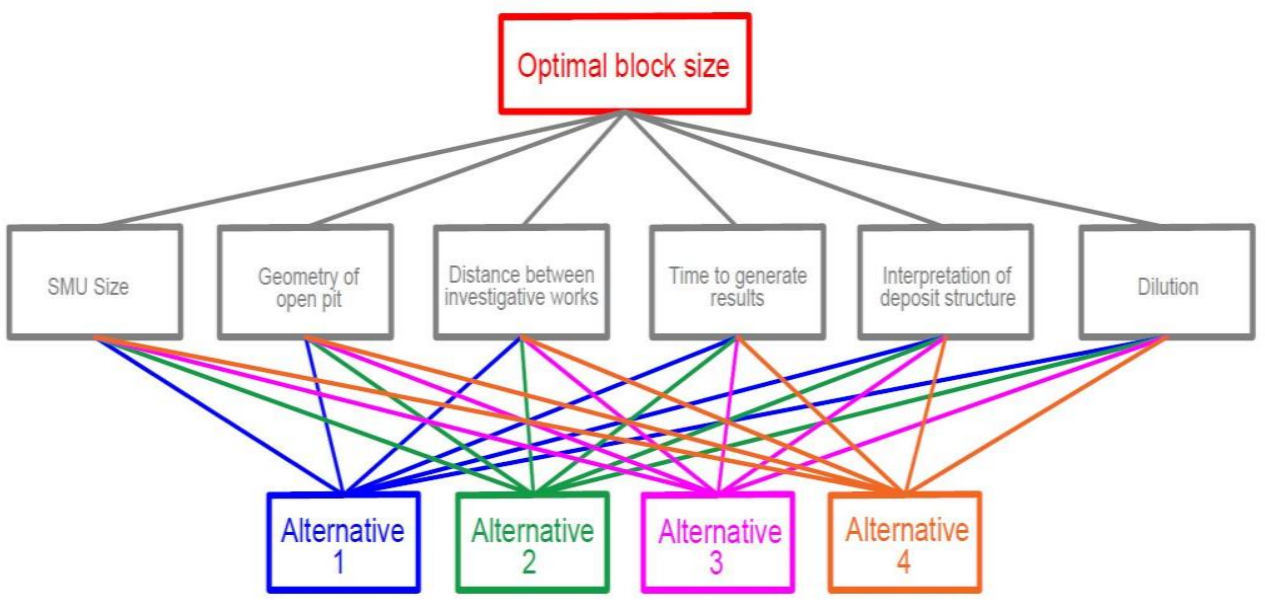

Figure 11 Structure of AHP model for optimal block size selection

\subsection{Analysis results}

After forming the appropriate structure of the problem, i.e. after defining the criteria and alternatives, the appropriate decision matrix was formed. The matrix was formed on the basis of qualitative assessments with the help of experts opinions. Rating and scoring of all qualitative criteria for each of the alternatives was performed based on the sevenfold range, shown in Table 3, while the formed decision matrix is shown by Table 4 .

Table 3 Scoring range for qualitative criteria (Mahdavi et al., 2008)

\begin{tabular}{|c|c|c|c|c|c|c|c|c|}
\hline $\begin{array}{l}\text { Expression } \\
\text { variable }\end{array}$ & $\begin{array}{l}\text { Very } \\
\text { low }\end{array}$ & low & $\begin{array}{l}\text { Low } \\
\text { interm } \\
\text { ediate }\end{array}$ & $\begin{array}{l}\text { Interme } \\
\text { diate }\end{array}$ & $\begin{array}{l}\text { High } \\
\text { inter } \\
\text { media } \\
\text { te }\end{array}$ & high & $\begin{array}{l}\text { Very } \\
\text { high }\end{array}$ & $\begin{array}{l}\text { Intermediate } \\
\text { states }\end{array}$ \\
\hline $\begin{array}{l}\text { Numerical } \\
\text { value }\end{array}$ & 0 & 1 & 3 & 5 & 7 & 9 & 10 & $2,4,6,8$ \\
\hline
\end{tabular}


Table 4 Decision Matrix based on the experts opinions

\begin{tabular}{ccccccc}
\hline & $\mathbf{C}_{\mathbf{1}}$ & $\mathbf{C}_{\mathbf{2}}$ & $\mathbf{C}_{\mathbf{3}}$ & $\mathbf{C}_{\mathbf{4}}$ & $\mathbf{C}_{\mathbf{5}}$ & $\mathbf{C}_{\mathbf{6}}$ \\
& $\begin{array}{c}\text { SMU } \\
\text { Size }\end{array}$ & $\begin{array}{c}\text { Geometry } \\
\text { of an open } \\
\text { pit }\end{array}$ & $\begin{array}{c}\text { Distance } \\
\text { between } \\
\text { investigative } \\
\text { works }\end{array}$ & $\begin{array}{c}\text { Time to } \\
\text { generate } \\
\text { results }\end{array}$ & $\begin{array}{c}\text { Interpretation } \\
\text { of deposit } \\
\text { structure }\end{array}$ & Dilution \\
\hline $\mathbf{A}_{1}$ & 9 & 3 & 9 & 3 & 9 & 9 \\
$\mathbf{A}_{2}$ & 8 & 4 & 9 & 5 & 7 & 7 \\
$\mathbf{A 3}_{3}$ & 4 & 6 & 7 & 7 & 3 & 5 \\
\hline $\mathbf{A} 4$ & 2 & 9 & 7 & 9 & 1 & 3 \\
\hline
\end{tabular}

The way in which the matrix is formed can be explained by the examples of interpretation of the deposit's structure, where it can be seen that Alternative 1 or blocks with dimensions of 20x20x1 m discretize the deposit in the best way, and according to this criterion, the first alternative received the highest grade, while other alternatives would receive a lower score, according to their level of deposit interpretation. This scoring method was applied to all other criteria.

The next step according to the AHP methodology was to define the weight coefficient of the considered criteria, which is shown in Table 5. These criteria were determined on the basis of double comparison matrix of the criteria according to the Saaty scale.

Table 5 Double comparison matrix of the criteria according to the Saaty scale

\begin{tabular}{lllllll}
\hline & $\mathbf{C}_{\mathbf{1}}$ & $\mathbf{C}_{\mathbf{2}}$ & $\mathbf{C}_{\mathbf{3}}$ & $\mathbf{C}_{\mathbf{4}}$ & $\mathbf{C}_{\mathbf{5}}$ & $\mathbf{C}_{\mathbf{6}}$ \\
\hline $\mathbf{C}_{\mathbf{1}}$ & 1.000 & 4.000 & 1.000 & 7.000 & 2.000 & 2.000 \\
$\mathbf{C}_{\mathbf{2}}$ & 0.250 & 1.000 & 0.250 & 4.000 & 0.500 & 0.500 \\
$\mathbf{C}_{\mathbf{3}}$ & 1.000 & 4.000 & 1.000 & 7.000 & 2.000 & 2.000 \\
$\mathbf{C}_{\mathbf{4}}$ & 0.143 & 0.250 & 0.143 & 1.000 & 0.330 & 0.330 \\
$\mathbf{C}_{5}$ & 0.500 & 2.000 & 0.500 & 3.030 & 1.000 & 1.000 \\
$\mathbf{C}_{6}$ & 0.500 & 2.000 & 0.500 & 3.030 & 1.000 & 1.000 \\
\hline
\end{tabular}

After the mutual relations of the criteria were defined by applying the Saaty scale, the weight coefficients were calculated by the mathematical solution of the matrix, and their values are shown in Table 6 . For the purpose of checking the consistency of the decision maker, the Consistency Index (CI) and the Consistency Rate (CR) were calculated, and their values are given in Table 7. Considering that the condition of the consistency is that 
the value of CR is less than $0.1(10 \%)$, it can be concluded that the obtained results confirmed that the decision is consistent because the value of CR in this case is 0.05176 $(5.2 \%)$.

Table 6 Weight coefficients of considered criteria

\begin{tabular}{lc}
\hline Criteria & Weight Coefficient \\
\hline SMU Size & 0.293 \\
Geometry of an open pit & 0.088 \\
Distance between investigative works & 0.293 \\
Time to generate results & 0.040 \\
Interpretation of deposit structure & 0.143 \\
Dilution & 0.143 \\
\hline
\end{tabular}

Table 7 Consistency check values

\begin{tabular}{lc}
\hline Maximum eigenvalue of the comparison matrix $(\lambda \max )$ & 6.32 \\
Random Consistency Index (RI) & 1.24 \\
Consistency Index (CI) & 0.06419 \\
Consistency Rate (CR) & 0.05176 \\
\hline
\end{tabular}

After defining the weight coefficients and checking the consistency, the AHP method was applied to obtain the optimal block size according to the set criteria. The final results of this analysis are shown in Table 8. The presentation of the results is also given through the graph shown in Figure 12, where it is possible to see which block size is the best, according to the considered analysis criteria.

Table 8 Analysis results and final ranking of alternatives

\begin{tabular}{ccccc}
\hline Alternative & Block size $\left(\mathbf{m}^{\mathbf{3}}\right)$ & $\begin{array}{c}\text { Final weight } \\
\text { coefficient of } \\
\text { alternatives }\end{array}$ & $\boldsymbol{\%}$ & Rank \\
\hline A1 & $\mathbf{2 0} \times \mathbf{2 0 \times \mathbf { 1 }}$ & $\mathbf{0 . 3 3 2 0 5 4}$ & $\mathbf{3 3 . 2}$ & $\mathbf{1}$ \\
\hline A2 & $20 \times 20 \times 2.5$ & 0.300402 & 30.0 & 2 \\
A3 & $15 \times 15 \times 5$ & 0.201955 & 20.2 & 3 \\
A4 & $15 \times 15 \times 10$ & 0.165589 & 16.6 & 4 \\
\hline
\end{tabular}




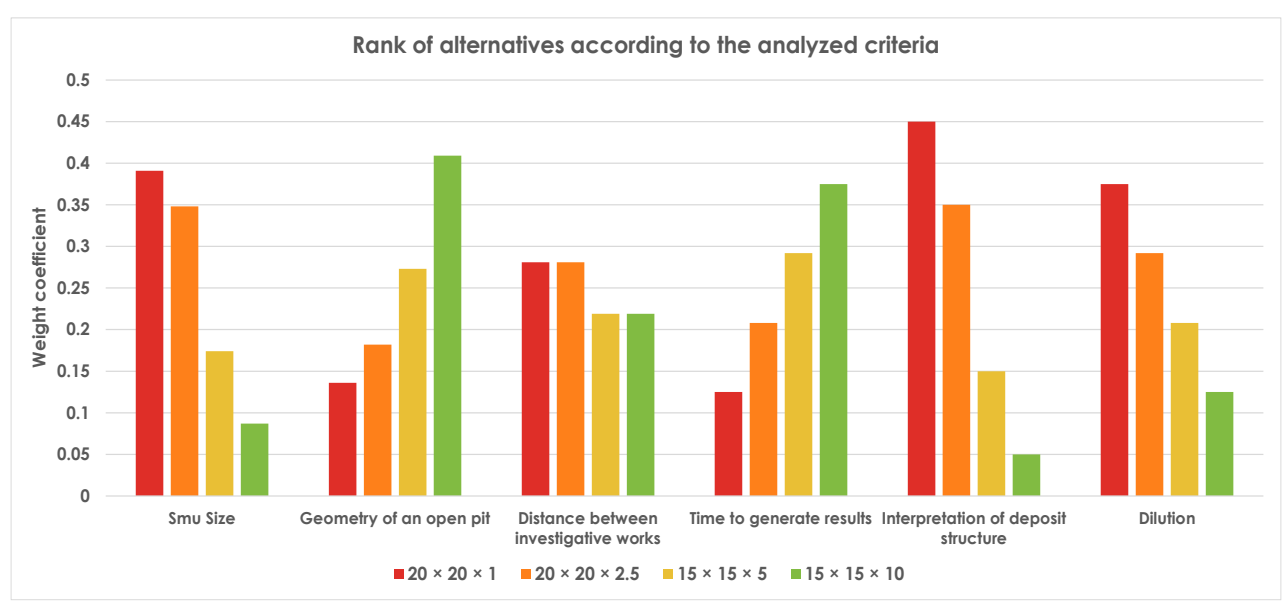

Figure 12 Results of ranking alternatives according to the analyzed criteria

\section{DISCUSSION AND CONCLUSION}

Reviewing the results shown in the graph from Figure 12, it can be concluded that larger blocks (alternatives A3 and A4) are better ranked according to criteria $\mathrm{C} 2$ and $\mathrm{C} 4$ (geometry of open pit and time to generation time), which is the result of their larger volume, as well as their better compatibility with the bench height. In contrast, smaller blocks are better ranked according to the other four criteria (SMU size, distance between investigative works, interpretation of deposit structure, dilution). Precisely because of this, alternatives $\mathrm{A} 1$ and $\mathrm{A} 2$, which represent smaller blocks, have stood out significantly, compared to the other two alternatives.

Alternative A1, which represents blocks of dimensions $20 \times 20 \times 1 \mathrm{~m}$, proved to be the final and optimal solution of analyzed alternatives. This block size is best aligned with the applied and planned technology, with the grid of exploration works as well as the need for selective excavation. Also, this block size provides the best fit of the block model volume with the solid volume and provides the possibility of additional discretization of the block height ("sub-block formation") from $1 \mathrm{~m}$ to $0.5 \mathrm{~m}$, which would highlight the contacts between coal and waste. This ensures an appropriate selectivity of $0.5 \mathrm{~m}$ in contact areas but does not significantly affect the increase in the overall number of blocks in the model.

As it can be seen, the block size of a deposit model may depend on a number of different criteria that cannot be clearly correlated with each other, due to their different unmeasurable values. For that reason, the application of the AHP method achieves the quantification of descriptive values, which undoubtedly establishes priority and hierarchy among different criteria. In addition, although the AHP method provides an optimal solution, this does not mean that one result is optimal in terms of all criteria. In this case, the implementation of the AHP method determined that the first alternative 
representing blocks of dimensions $20 \times 20$ x $1 \mathrm{~m}$, is optimal for this case study. However, this does not mean that these block dimensions are optimal for all six criteria, so the result obtained by AHP method is more appropriately defined as an optimal compromise.

Although the AHP method, allows the quantification of expert judgment in multicriteria analysis, the lack of objectivity in expert judgment can often be questioned. This is the biggest defect of the AHP method, so, in order to check the results and achieve their validity, an objective assessment of several different experts is proposed, based on which the optimal result can be defined, as was done in this paper.

Further scientific work, should certainly be directed towards the more detailed understanding of the nature of the problem to define additional criteria, possibly not covered, as well as a more precise mathematical definition of the used ones.

\section{REFERENCES}

ABDOLLAHI, S., JAFARPOUR A. and YOUSEFI, S. (2020) A Hybrid Fuzzy MCDM Approach to Determine an Optimal Block Size in Open-Pit Mine Modeling: a Case Study. Journal of Mining and Environment (JME), 11(2), 611-627.

COOMBES, J. (2004) Resource Estimation. Snowden Mining Industry Consultants.

CUPIĆ, M.; TUMMALA, R. and SUKNOVIĆ, M. (2001) Decision making: formal approach. Belgrade: Faculty of Organizational Sciences.

DAVID , M. (1971) Geostatistical Ore Reserve calculation, step by step Case Study. Decision Making in the Mineral Industry. CIM Bulletin, 12, 185-191.

DAVID , M. (1977) Geostatistical Ore Reserve Estimation. Amsterdam: Elsevier.

DJENADIĆ, S. et al. (2019) Development of the Availability Concept by Using Fuzzy Theory with AHP Correction, a Case Study: Bulldozers in the Open-Pit Lignite Mine. Energies, 12(21), 4044.

HAYATI, M., RAJABZADEH, R. and DARABI, M. (2015) Determination of optimal block size in Angouran mine using VIKOR method. Journal of Materials and Environmental Science, 6(11), 3236-3244.

JANKOVIĆ, I. et al. (2019) Multi-Criteria Approach for Selecting Optimal Dozer Type in Open-Cast Coal Mining. Energies, 12(12), 2245.

JOURNEL, A. G. and HUIJBREGTS, C. J. (1978) Mining geostatistics. New York: Academic Press London.

LEE, A. H. I., CHEN, W. C. and CHANG, C. J. (2008) A fuzzy AHP and BSC approach for evaluating performance of IT department in manufacturing industry in Taiwan. Expert Systems with Application, 34, 96-107. 
LEUANGTHONG O., NEUFELD C. and DEUTSCH C. V. (2003) Optimal Selection of Selective Mining Unit (SMU) Size. (pp. 1-16). Santiago, Chile: International Conference on Mining Innovation (MININ).

MAHDAVI I. et al. (2008) Designing a model of fuzzy TOPSIS in multiple criteria decision making. Applied Mathematics and Computation, 206(2), 607-617.

RAHIMDEL, M. J. and BAGHERPOUR, R. (2018) Haulage system selection for open pit mines using fuzzy MCDM and the view on energy saving. Neural Computing and Applications, 29(6), 187-199.

SAATY T. L. and VARGA L. G. (2012) Models, Methods, Concepts \& Applications of the Analytic Hierarchy Process ISBN 978-1-4614-3596-9/ISSN 0884-8289/e-ISBN 978-978-1-4614-3596-6. (2nd ed.). New York: Springer.

SAATY, R. (1987) The Analytic Hierarchy Process. Mathematical Modelling, 9(3-5), 161-176.

SAATY, T. (1980) The Analytical Hierarchy Process. New York, NY, USA: Mc-GrawHill.

SAATY, T. (2003) Decision Making with the AHP: Why is the Principal Eigenvector Necessary? European Journal of Operational Research, 145, 85-91.

SINCLAIR, A. and BLACKWELL G. (2002) Applied Mineral Inventory Estimation. United Kingdom: Cambridge University Press.

SITORUS, F. CILLIERS, J.J. and BRITO-PARADA, P.R. (2019) Multi-criteria decision making for the choice problem in mining and mineral processing: Applications and trends. Expert Systems with Applications, 121, 393-417.

STEVANOVIĆ, D. (2015) Optimization and planning of surface mines by stochactic models. Belgrade: University of Belgrade, Faculty of Mining and Geology.

STEVANOVIĆ, D. et al. (2020) Application constraines of optimization algorithms in the case of coal mines. Proceedings of the XIV International Conference OMS 2020 (pp. 76-87). Zlatibor: Yugoslavian Committee for Surface Exploitation: Belgrade, Serbia.

STEVANOVIĆ, D. et al. (2018) Application of MCDA in selection of different mining methods and solutions. Advances in Science and Technology. Research Journal, 12(1), 171-180. 